\title{
Holmium laser vs. conventional (cold knife) direct visual internal urethrotomy for short-segment bulbar urethral stricture: Outcome analysis
}

\author{
Ankur Jhanwar, MD; Manoj Kumar, MD; Satya Narayan Sankhwar, MD; Gaurav Prakash, MD \\ King George's Medical University, Lucknow, India
}

Cite as: Can Urol Assoc J 2016;10(5-6):E161-4. http://dx.doi.org/10.5489/cuai.3382 Published online May 12, 2016.

\section{Abstract}

Introduction: Our goal was to analyze the outcome between holmium laser and cold knife direct visual internal urethrotomy (DVIU) for short-segment bulbar urethral stricture.

Methods: We conducted a prospective study comprised of 112 male patients seen from June 2013 to December 2014. Inclusion criterion was short-segment bulbar urethral stricture $(\leq 1.5 \mathrm{~cm})$. Exclusion criteria were prior intervention/urethroplasty, pan-anterior urethral strictures, posterior stenosis, urinary tract infection, and those who lost to followup. Patients were divided into two groups; Group A $(n=58)$ included cold knife DVIU and group B $(n=54)$ included holmium laser endourethrotomy patients. Patient followup included uroflowmetry at postoperative Day 3, as well as at three months and six months.

Results: Baseline demographics were comparable in both groups. A total of 107 patients met the inclusion criteria and five patients were excluded due to inadequate followup. Mean stricture length was $1.31 \pm 0.252 \mathrm{~cm}(\mathrm{p}=0.53)$ and $1.34 \pm 0.251 \mathrm{~cm}$ in Groups $A$ and $B$, respectively. Mean operating time in Group A was $16.3 \pm$ $1.78 \mathrm{~min}$ and in Group B was $20.96 \pm 2.23 \mathrm{~min}(\mathrm{p}=0.0001)$. Five patients in Group A had bleeding after the procedure that was managed conservatively by applying perineal compression. Three patients in Group B had fluid extravasation postoperatively. Qmax $(\mathrm{ml} / \mathrm{s})$ was found to be statistically insignificant between the two groups at all followups.

Conclusions: Both holmium laser and cold knife urethrotomy are safe and equally effective in treating short-segment bulbar urethral strictures in terms of outcome and complication rate. However, holmium laser requires more expertise and is a costly alternative.

\section{Introduction}

Urethral stricture is one of the oldest known urological problems and it continues to be common and often challenging. Multiple treatment modalities have evolved over the years.
The three most commonly performed procedures for urethral stricture disease are urethral dilatation, optical urethrotomy, and urethroplasty.

We are curently in an era focused on minimally invasive endoscopic procedures ${ }^{1,2}$ however, urethral stricture is one of the rare medical issues for which the success rate of open reconstructive urethroplasty is far better than more minimally invasive alternatives.

Cold knife optical internal urethrotomy was popularized after the work of Sachse in $1974 .{ }^{3}$ Since then, several other endoscopic alternatives have been included in the urological armamentarium for the treatment of urethral stricture disease. Holmium laser was one of them, introduced for the treatment of urethral stricture disease in the early 90s. Holmium YAG laser works based on vaporization at a wavelength of 2140 $\mathrm{nm}$ and its depth of penetration is approximately $0.5 \mathrm{~mm}$. Other lasers used for urethral stricture disease include carbon dioxide, Nd:YAG, KTP, argon, and excimer lasers, but superiority of one laser over the other has not been mentioned in literature. ${ }^{4,5}$ Urethrotomy has been performed either under general or regional anaesthesia. Some authors reported excellent results under local anaesthesia. ${ }^{6,7}$

\section{Methods}

This prospective study - conducted after obtaining ethical review board committee approval and an informed written consent from all included patients - looked at patients in the urology department of a tertiary care teaching institute in Northern India from June 2013 to December 2014. A total of 107 patients of aged 17-64 years met the inclusion criteria of having shortsegment bulbar urethral stricture $(\leq 1.5 \mathrm{~cm})$, evident by symptoms of weak urinary stream and confirmation on radiological studies (i.e., retrograde urethrography [RGU] and micturating cystourethrography [MCU]). Exclusion criteria were patients with multiple strictures, pan-anterior urethral strictures, posterior stenosis, failed prior intervention, lichen sclerosis changes, urinary tract infection, and those lost to followup. 
Prior to intervention patients underwent complete physical examination, urine routine with culture and sensitivity, uroflowmetry, and blood investigation. The site and size of urethral stricture was noted. Appropriate antibiotic was administered pre- and post-intervention.

Patients were allocated into either Group A or Group B in a 1:1 ratio. Group A consisted of those who underwent cold knife (Sachse) procedure and Group B of those who underwent holmium laser internal urethrotomy. Patients were followed with uroflowmetry (as there was no uniformly accepted method of followup after DVIU) and any complaints noted at postoperative Day 3, as well as after three and six months. The Visual Analogue Scale score (VAS) was taken in both groups at three, six, 12, and 24 hours postoperatively. Our protocol for postoperative analgesics was patients demand or VAS $>5$. Operating time was calculated from insertion of cystoscope into meatus to the removal of urethrotome or laser fibre with the cystoscope out of meatus.

\section{Technique}

Both the procedures were done under local anaesthesia using mixture of $20 \mathrm{ml}$ of $2 \%$ lignocaine jelly mixed with $2 \mathrm{ml}$ of $1 \%$ lignocaine solution, pushed slowly into the urethral lumen with the help of syringe and left for 5-7 mins.

\section{Cold knife}

In lithotomy position, a cystoscopic-assisted guidewire was negotiated beyond the stricture site. Once the position of the guidewire in the urinary bladder was confirmed, the cystoscope was withdrawn and the Sachse cold knife urethrotome, using $21 \mathrm{Fr}$ sheath and 0 degree telescope, advanced into the urethra. The stricture was incised at the 12 o'clock position (single or multiple times until it adequately opened up and allowed negotiation of the scope into the bladder). While withdrawing the scope, the stricture site was inspected; if there was some fibrosis remaining, then it was incised. A Foley catheter (14 Fr) was then placed per urethraly.

\section{The holmium laser}

Once the stricture site was located, the holmium laser fibre $(365 \mu \mathrm{m})$ was introduced through a side channel of 17 Fr sheath and 0 degree scope. The holmium laser (Versa PowerSuite) with power settings (0.6-1.2 Joules, 6-12 Watts) was used. To avoid thermal injury, the fibre was placed a few $\mathrm{mm}$ away from the scarred tissue. The stricture was incised at the $12 \mathrm{o}^{\prime}$ clock position and once the scope was negotiated beyond the stricture and up to the bladder, the scope was withdrawn slowly and a $14 \mathrm{Fr}$ foley catheter was inserted per urethrally.
Per urethral catheter removal and voiding trial was given at postoperative Day 3 in both groups.

\section{Statistical analysis}

The results were presented in mean \pm standard deviation (SD) and percentages. The unpaired t-test was used to compare two independent means. Paired t-test was used to compare the variables in preoperative and postoperative periods. A $p$ value $<0.05$ was considered statistically significant. All the analysis was carried out using SPSS 16.0 versions (Chicago, Inc., U.S.).

\section{Results}

Baseline demographics were comparable in both groups (Table 1). Data from 107 patients were analyzed. Five patients were excluded due to inadequate followup. The mean \pm SD age in Groups A and B was $39.38 \pm 13.4$ and $38.13 \pm 12.3$ years, respectively $(p=0.61)$. The mean $\pm S D$ operating time in Group A was $16.3 \pm 1.78$ minutes, while in Group B it was $20.96 \pm 2.23$ minutes $(p=0.0001)$. The mean length of stricture in Group A was $1.31 \pm 0.252 \mathrm{~cm}$ and in Group B was $1.34 \pm 0.251 \mathrm{~cm}(p=0.53)$. The mean VAS (pain score) in Group A was $4.1 \pm 1.68$ and in Group $B$ was $3.9 \pm 1.59$. The duration of per urethral catheterization was 72 hours in both groups. Preoperative Qmax $(\mathrm{ml} / \mathrm{s})$ in Group A was $5.3 \pm 1.98$ and in Group B was $5.8 \pm 2.1$ $(p=0.207)$. The mean Qmax $(\mathrm{ml} / \mathrm{s})$ on postopertive Day 3, as well as at three months and six months in Group A was $21.4 \pm 2.75,23.4 \pm 2.71$, and $23.7 \pm 2.74$, respectively. The mean Qmax ( $\mathrm{ml} / \mathrm{s})$ on postopertive Day 3, as well as at

\begin{tabular}{|c|c|c|c|}
\hline Parameter & $\begin{array}{l}\text { Cold knife } \\
\text { DVIU }\end{array}$ & $\begin{array}{l}\text { Holmium } \\
\text { laser }\end{array}$ & $p$ value \\
\hline Age & $39.38 \pm 13.4$ & $38.13 \pm 12.3$ & 0.61 \\
\hline Mean length of stricture & $1.31 \pm 0.252$ & $1.34 \pm 0.251$ & 0.53 \\
\hline Mean operating time & $16.3 \pm 1.78$ & $20.96 \pm 2.23$ & 0.0001 \\
\hline Preoperative $0 \max (\mathrm{ml} / \mathrm{s})$ & $5.3 \pm 1.98$ & $5.8 \pm 2.1$ & 0.207 \\
\hline \multicolumn{4}{|l|}{ Postoperative Qmax (ml/s) } \\
\hline At Day 3 & $21.4 \pm 2.75$ & $21.7 \pm 2.73$ & 0.569 \\
\hline At 3 months & $23.4 \pm 2.71$ & $23.6 \pm 2.72$ & 0.703 \\
\hline At 6 months & $23.7 \pm 2.74$ & $23.8 \pm 2.78$ & 0.851 \\
\hline Complications & $12.7 \%$ & $9.6 \%$ & \multirow{4}{*}{0.764} \\
\hline Bleeding & 5 & 0 & \\
\hline Fever & 0 & 2 & \\
\hline Fluid extravasation & 2 & 3 & \\
\hline Mean VAS pain score & $4.1 \pm 1.68$ & $3.9 \pm 1.59$ & 0.51 \\
\hline $\begin{array}{l}\text { Number of patients } \\
\text { require reintervention }\end{array}$ & $4(7.27 \%)$ & $4(7.69 \%)$ & 1 \\
\hline
\end{tabular}




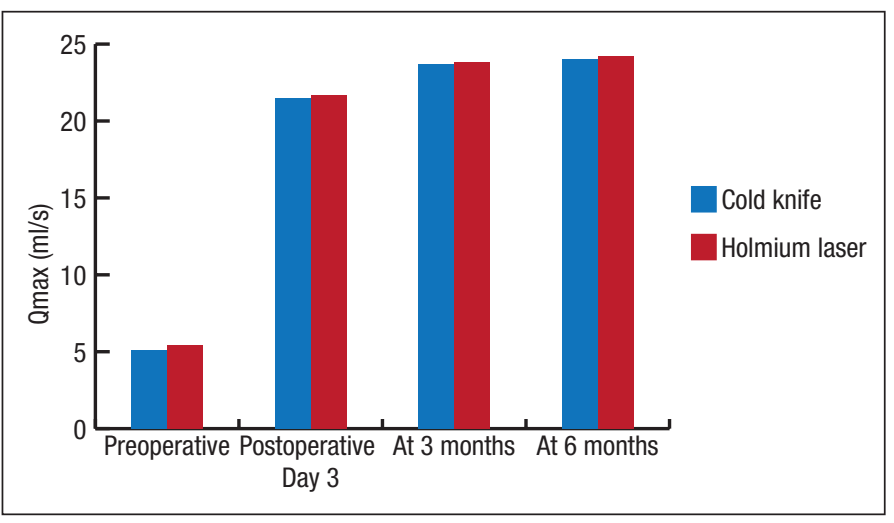

Fig. 1. $0 \mathrm{max}(\mathrm{ml} / \mathrm{s})$ at followup between two modalities.

three months and six months in Group B was $21.7 \pm 2.73$, $23.6 \pm 2.72$, and $23.8 \pm 2.78$, respectively (Fig. 1).

\section{Discussion}

Urethral stricture is the narrowing of urethral lumen due to fibrosis secondary to inflammation or trauma. Different treatment modalities with variable results are available. The one that is most appealing to urologists and patients is DVIU, as it is a minimally invasive, outpatient, endoscopic procedure.

DVIU as a surgical treatment for urethral stricture was popularized after the initial report of Sachse in $1974 . .^{3,8}$ Since 1984, different lasers have been introduced in the stricture treatment armamentarium. No currently available data report superiority of one laser over another. The advantage of Ho:YAG laser is its coagulation ability and shallow absorption $(0.5 \mathrm{~mm})$; it is presumed to reduce scar tissue formation.

In their studies, Steenkamp et al (1997), Choong et al (1997), and Munks et al (2010) reported that the procedure of internal urethrotomy is very well-tolerated by the patient under local anesthesia. Similarly, in this study we also use local anesthesia and observed that patients tolerate the procedure well.

In their study of 51 male patients with single, iatrogenic stricture, Atak et al observed shorter operative time in lasertreated patients ( $n=21,16.4 \pm 8.04$ minutes) vs. cold knifetreated patients ( $\mathrm{n}=30,23.8 \pm 5.47$ minutes). ${ }^{9}$ Kamal reported mean operative time of 22.3 minutes using a diode laser. ${ }^{10}$

In our study, mean operative time for the cold knife group was $16.3 \pm 1.78$ minutes, which is shorter than in the study done by Atak et al (23.8 \pm 5.47 minutes) and longer than the study by Jain et al (7.44 minutes). ${ }^{9,11}$ The mean operative time in the holmium laser group was $20.96 \pm 2.23$ minutes in our study, which is comparable to the study done by Jain et al (19.8 minutes). ${ }^{11}$ The VAS score in Groups A and B was $4.1 \pm 1.68$ and $3.9 \pm 1.59$, respectively.

In our study, catheter removal and voiding trial was given on Day 3, as there is no convincing evidence in the literature that increasing the duration of catheterization has a positive impact on outcome. Albers et al reported that urethral catheterization left for $\leq 3$ days following DVIU is associated with lower recurrence rate compared with longer duration (34\% vs. $43 \%) .{ }^{12}$ Dutkiewicz et al reported increased chance of urinary tract infection following prolonged catheterization. ${ }^{13}$ In their studies, Heyns et al and Steenkamp et al reported 1-4 days of catheterization following urethrotomy. ${ }^{14,15}$

No major complications occurred in our study. Five patients (9.1\%) in Group A had bleeding, two patients in each group had fever, and three patients (5.7\%) in Group B had fluid extravasation. All were managed conservatively. No patient in our study had post-procedural incontinence or impotence.

As the outcome criteria is not standardized following DVIU, we followed our patients with uroflowmetry (Qmax $\mathrm{ml} / \mathrm{s}$ ). In this study, we did not observe any statistically significant difference in followup Qmax between the two groups.

Hussain et al reported that good results are achieved if post-procedure Qmax is $>15 \mathrm{ml} / \mathrm{s}$ and there is no need for any other intervention. ${ }^{16}$ In this study, four patients in Group A required one more urethrotomy, two at three-month and two others at six-month followups. Similarly, four patients in Group B required another intervention, one at three-month and three at six-month followups. In all eight patients, Qmax was $<10 \mathrm{ml} / \mathrm{s}$, which was considered failure according to our protocol. The recurrence in Group A might have been due to inadequate division of fibrous tissue leading to nonseparation of scarred tissue and, subsequently, no healing by secondary intention. The recurrence in Group B might have been due to inadequate cutting of scarred tissue, as there is lack of sense of depth perception with holmium laser.

In our study, clean intermittent catheterization $(\mathrm{CIC})$ was advised for all patients following their procedure. Our protocol for CIC was once-daily for a week, then twice-weekly for three weeks, then once-weekly for three months. Surprisingly, no patient found difficulty in doing $\mathrm{CIC}$. The theory behind $\mathrm{CIC}$ following DVIU is that the process of self-catheterizsation prevents the scar from contracting while it matures. Lawrence et al conducted a study on 42 patients and demonstrated excellent results for postoperative $\mathrm{CIC}$ for three months. ${ }^{17}$ Kjaeergard et al and Harris et al also observed lower recurrence rate in those who were on $\mathrm{ClC} .{ }^{18,19}$

In our study, we did not observe any statistically significant difference between the recurrence rates in both group. Four patients had recurrence in each group. This result may be due to short-term followup and strict inclusion criteria, as it may be different for long-term followup; other segments may have different recurrence rates, which was not analyzed in this study.

Jin et al did a meta-analysis including 3230 cases from 44 articles. ${ }^{20}$ They reported a better success rate with holmium laser urethrotomy compared to cold knife technique (74.9\% vs. $68.5 \%)$. 
The limitations of our study were selection of only shortsegment bulbar urethral stricture and short followup.

\section{Conclusion}

Both conventional (cold knife) and holmium laser urethrotomy are equally effective in terms of outcome and safety for short-segment bulbar urethral stricture. The holmium laser offers a significant advantage with its coagulation ability. However, use of holmium laser requires more expertise and its availability is a limitation. As urethral stricture may recur, further long-term comparative studies comparing these two modalities are required.

Competing interests: The authors declare no competing financial or personal interests.

This paper has been peer-reviewed.

\section{References}

1. de Kock ML, Allen FJ. Guidelines for the treatment of urethral strictures. S Afr J Surg 1989; 27:182-4.

2. Sandozi $S$, Ghazali $S$. Sachse optical urethrotomy, a modified technique: 6 years of experience. J Urol 1988; 140:968-9.

3. Sachse H. Zur behandlung der Harnrohrenstriktur; Die transurethrale Schlitzung unter Sicht mit scharfen Schnitt. Fortschr Med 1974;92:12-5.

4. Wein AJ, Kavoussi LR, Novick AC, et al. 10th ed. Philadelphia: Elsevier Saunders 2012. Campbell Walsh Urology pp. 967-73.

5. Hermann TR, Liatsikos EN, Nagele U, et al. EAU guidelines on laser technologies. Eur Urol 2012;61:78395. http://dx.doi.org/10.1016/.eururo.2012.01.010

6. Greenland JE, Lynch TH, Wallace DMA. Optical urethrotomy under local urethral anesthesia. Br J Urol 1998:67:385-8. http://dx.doi.org/10.1111/i.1464-410X.1991.tb15167.x
7. Ather MH, Zehri AA, Soomro K, et al. The safety and efficacy of optical urethrotomy using a spongiosum block with sedation: A comparative nonrandomized study. J Urol 2009;181:2134-8. http://dx.doi. org/10.1016/i.juro.2009.01.017

8. Sachse H. Die transurethrale scharfe Schlitzung der Harnrohrenstriktur unter Sicht. Munsch Med Wschr 1974;116: 2147.

9. Atak M, Tokgoz H, Akduman B, et al. Lowpower holmium: YAG laser urethrotomy for urethral stricture disease: Comparison of outcomes with the coldknife technique. Kaohsiung J Med Sci 2011;27:503-7. http://dx.doi.org/10.1016/i.kims.2011.06.013

10. Kamal BA. The use of the diode laser for treating urethral strictures. BJU Int 2002;87:831-3. http:// dx.doi.org/10.1046/i.1464-410x.2001.02183.x

11. Jain SK, Kaza RC, Singh BK. Evaluation of holmium laser versus cold knife in optical internal urethrotomy for the management of short segment urethral stricture. Urol Ann 2014;6:328-33. http://dx.doi. org/10.4103/0974-7796.140997

12. Albers $P$, Fichtner J, Bruhl P, et al. Long-term results of internal urethrotomy. J Urol 1996;156:1611-4. http://dx.doi.org/10.1016/S0022-5347(01)65461-2

13. Dutkiewicz SA, Wroblewski M. Comparison of treatment results between holmium laser endourethrotomy and optical internal urethrotomy for urethral stricture. Int Urol Nephrol 2012;44:717-24. http://dx.doi. org/10.1007/s1 1255-011-0094-8

14. Heyns CF, Steenkamp JW, De Kock ML, et al. Treatment of male urethral strictures: Is repeated dilatation or urethrotomy useful. J Urol 1998; 160:356-8. http://dx.doi.org/10.1016/S0022-5347(01)62894-5

15. Steenkamp JW, Heyns CF, de Kock MI. Internal urethrotomy versus dilatation as treatment for male urethral strictures.A prospective randomized comparison. J Urol 1997;157:98-101. http://dx.doi.org/10.1016/ S0022-5347(01)65296-0

16. Hussain M, Lal M, Askari SH, et al. Holmium laser urethrotomy for treatment of traumatic stricture urethra: A review of 78 patients. J Pak Med Assoc 2010;60:829-32.

17. Lawrence WT, MacDonagh RP. Treatment of urethral stricture disease by internal urethrotomy followed by intermittent 'low-friction' self-catheterization: Preliminary communication. J Roy Soc Med 1988;81:136-8.

18. Kjaeergard B, Walter $S$, Bartholin J, et al. Prevention of urethral stricture recurrence using clean intermittent self-cathterization. Jr J Urol 1994;73:692-5. http://dx.doi.org/10.1111/j.1464-410X.1994. tb07558.x

19. Harriss DR, Beckingham IJ, Lembergher RJ, et al. Long-term results of intermittent low-friction selfcatheterization in patients with recurrent urethral strictures. Br I Urol 1994;74:790-7. http://dx.doi. org/10.1111/i.1464-410X.1994.tb07127.x

20. Jin $T$, Li H, Jiang $L H$, et al. Safety and efficacy of laser and cold knife urethrotomy for urethral stricture. Chin Med J (Engl) 2010;123:1589-95.

Correspondence: Dr. Ankur Jhanwar, King George's Medical University, Lucknow, India; drankurstanley01@gmail.com 